\title{
Dinero y poder en la intimidad de pareja en Argentina: indicios desde una mirada de género y clase social
}

\section{Money and Power in Argentinean Couples' Relationships: Evidence from a Gender and Social Class Perspective}

Gonzalo Seid ${ }^{*}$ Gabriela Gómez Rojas²

Recibido: 25 de agosto

2020

Aceptado: o3 de marzo de

2021

Publicado: 14 de junio de 2021

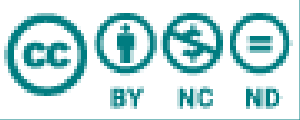

Esta obra está protegida bajo una

Licencia Creative Commons

Atribución-NoComercial-

SinDerivadas 4.0 Internacional ICC

BY-NC-ND 4.0)

\section{Resumen}

El objetivo de este artículo es presentar resultados de un estudio exploratorio acerca de la administración del dinero en parejas heterosexuales en Argentina (2010-2015). Se examinó información cuantitativa para la muestra argentina de la encuesta de 2012 del International Social Survey Programme (ISSP). Asimismo, se analizó una pregunta específica respecto del manejo del dinero

CÓMO CITAR: Seid, Gonzalo y Gómez Gabriela. (2021). Dinero y poder en la intimidad de pareja en Argentina: indicios desde una mirada de género y clase social. Revista Interdisciplinaria de Estudios de Género de El Colegio de México, 7, e698. doi: http://dx.doi.org/10.24201/reg.v7i1.698 
en 60 entrevistas cualitativas a mujeres y hombres de distintas clases sociales. Se hallaron tendencias similares a las reportadas en otros países: el administrador único está más asociado a concepciones de género tradicionales, mientras que el fondo común y las cuentas separadas se asocian a nociones de género más igualitarias. Se concluye que dentro de cada modalidad de manejo del dinero varían los arreglos concretos y sus efectos sobre desigualdades de género y clase.

Palabras clave: género; parejas; ingreso familiar; economía doméstica; clase social.

\begin{abstract}
The objective of this article is to present results of an exploratory study on heterosexual couples' money management in Argentina (2010-2015). We analyzed quantitative information for the Argentinean sample from the 2012 International Social Survey Program (ISSP). We also examined responses to a specific question about money management included in 60 qualitative interviews with women and men from different social classes. We found similar trends to those reported in other countries: the whole wage system is associated with more traditional gender values, whereas shared or independently managed accounts are both linked to more egalitarian gender values. We conclude that variations exist in couples' specific arrangements and in their effects on gender and class inequalities within each type of money management.
\end{abstract}

Keywords: gender; couples; family income; domestic economics; social class.

\title{
Introducción
}

El manejo del dinero en parejas heterosexuales expresa y moldea relaciones de poder. La clase social individual de la mujer y del varón condiciona las modalidades de administración del dinero que adopta una pareja. Durante buena parte del siglo pasado, el modelo familiar 
de hombre proveedor y mujer ama de casa implicaba el control masculino de las finanzas familiares. Desde la década de 1970, con el ascenso de los hogares de dos proveedores, en los cuales ambos miembros de la pareja heterosexual trabajan fuera del hogar y perciben ingresos, los arreglos familiares en torno al dinero adoptaron distintas formas, algunas más igualitarias que otras. Las transformaciones en los hogares dieron lugar a debates sociológicos respecto de la clase social individual de hombres y mujeres. En este marco, desde la década de 1980 cobraron impulso las investigaciones acerca de las maneras en que las parejas organizan los aportes de ingresos y las responsabilidades de los gastos, las condiciones de las que dependen y los efectos en otras dimensiones del poder en la vida familiar (Pahl, 1983).

En el presente artículo se muestran los resultados de un estudio exploratorio, de principios de la última década, acerca de la administración del dinero en parejas heterosexuales en Argentina. En primer lugar, se sintetizan discusiones teóricas y antecedentes de la bibliografía anglosajona acerca del reparto de ingresos y gastos en las parejas. En segundo lugar, se mencionan abordajes latinoamericanos referidos a dinámicas familiares, dinero y género. En tercer lugar, se presentan las decisiones metodológicas de esta investigación, los hallazgos cuantitativos acerca del manejo del dinero en los hogares argentinos en 2012 y un análisis cualitativo de entrevistas realizadas entre 2010 y 2015 a varones y mujeres viviendo en pareja en Buenos Aires y Mendoza. Finalmente, se presentan las conclusiones del artículo.

\section{Antecedentes}

Durante buena parte del siglo Xx, la extensión del modelo de marido proveedor y esposa dependiente en las familias occidentales, dio lugar a la naturalización de determinadas formas de administrar el dinero del hogar. En las parejas heterosexuales, típicamente el varón retenía el control financiero y le daba dinero a la esposa para los gastos comunes, como una especie de subsidio para el mantenimiento del hogar (allowance system). La mujer administraba esa "caja chica" para gastos cotidianos. Así, mientras los hombres proveedores se reservaban para sí una parte sustantiva de los ingresos familiares, las mujeres vieron incrementada su dependencia financiera al punto de que, en algunos casos, el "subsidio" ni siquiera incluía lo 
necesario para sus gastos personales. Lejos de empoderarlas, el manejo del dinero para las compras cotidianas, por parte de la esposa, era un trabajo doméstico rutinario más.

Desde el último cuarto del siglo pasado, las transformaciones en el mundo del trabajo y en las relaciones de género, como el aumento del número de parejas en las que ambos aportan ingresos, produjeron que el modelo hegemónico del "subsidio" del proveedor comenzara a declinar (Pahl, 1983) y se diversificaran las modalidades de administración del dinero doméstico. En este contexto, especialmente en los países anglosajones, emergió el interés sociológico y de los estudios de género por conocer las maneras en que se manejaba, repartía y controlaba el dinero entre los miembros de las parejas. Los primeros estudios del tema se basaban en la teoría de los recursos de poder (Blood y Wolfe, 1960), que postulaba que el cónyuge con más recursos (dinero, educación, profesión) tiene más poder en la toma de decisiones y en las negociaciones de pareja. Así, cuanto mayor sea la proporción de ingreso que un miembro aporta, o bien cuando su clase social sea superior, más grande será la probabilidad de que tome las decisiones financieras.

Una pregunta básica en los estudios referentes al manejo del dinero en el hogar ha sido, ¿qué condiciones hacen más probable una u otra modalidad de administración? La elección del sistema de manejo del dinero se encontró vinculada con el nivel de ingreso familiar: reunir los ingresos fue más común en situaciones de pobreza familiar, mientras que mantenerlos separados fue más probable con la prosperidad. Sin embargo, ya en la década de 1980 comenzó a advertirse que cuando la mujer era la principal aportante de ingresos, el manejo del dinero doméstico era diferente: en los hogares británicos ellas cedían parte del poder financiero a sus esposos, permitiéndoles el acceso a los ingresos de maneras igualitarias por ejemplo, mediante fondo común - en lugar de darles una parte (allowance system) para sus gastos comunes y personales (Stamp, 1985).

Estos estudios también se preguntaron a qué tipo de gastos se destinaban los ingresos de hombres y mujeres. Aunque ellas aportaran dinero, el modelo tradicional de varón proveedor orientaba a que los ingresos de ellos se destinaran al sustento cotidiano del hogar y los de las mujeres a gastos extraordinarios. Los primeros estudios hallaron que los ingresos de las 
casadas, especialmente cuando estos eran inestables, no se destinaban a las necesidades básicas de la familia, sino al ahorro o a ciertos consumos que mejoraban el estilo de vida familiar, en línea con la idea de ingreso complementario.

McRae (1987) analizó los patrones de reparto de gastos en familias británicas en las que la esposa tenía una ocupación no manual o profesional y el marido un trabajo manual, es decir, ella pertenecía a una clase ocupacional superior a la de él. La mayoría de las mujeres entrevistadas en su investigación asumían las responsabilidades de pago de hipotecas o alquileres, servicios y compras grandes. Además del monto y de la seguridad del ingreso, otro factor influyente en el reparto de gastos fue el modo en que se recibían las remuneraciones: en efectivo, mediante cheque o cuenta bancaria. Cuando el marido cobraba en efectivo, la esposa tendía a usar ese dinero disponible para las compras; si era mediante cheque, ella usaba su propio ingreso o bien tomaba dinero del fondo común. Tener un matrimonio previo influía en el sistema de administración escogido: cuando alguno ya se había casado antes, fue más común que usara el sistema independiente.

Si bien el nivel de ingreso individual influye en el poder de decisión en la pareja, la relación entre estos dos factores no es lineal. Muchas parejas en las que la mujer detenta una posición superior usan el sistema de fondo común, lo que podría expresar un esfuerzo por "disimular" las diferencias en el ingreso que favorecen a la mujer. El sistema de fondo común, al considerar el dinero como familiar y no individual, permitiría igualar a los cónyuges dentro del hogar, aunque permanecieran desiguales fuera (McRae, 1987).

Los estudios sociológicos y de género anglosajones acerca de la temática tuvieron en común el rechazo al abordaje de los economistas de concebir los hogares como unidades indivisibles con ingresos y gastos. Al cambiar el foco de atención hacia los individuos, el control del dinero por parte de hombres y mujeres en el hogar pasó a ser un mecanismo que intermedia entre ingresos y gastos. Los patrones de gastos no dependen solamente del monto de ingresos de un hogar ni tampoco exclusivamente de si hay uno o más proveedores. Pahl (1990) encontró que las mujeres británicas, aunque tuvieran un menor nivel de ingreso individual que sus esposos, contribuían con una mayor proporción de sus ingresos para los gastos 
comunes y reservaban menos para los personales. Cuando los varones eran los principales aportadores y las mujeres se ocupaban de los consumos para necesidades comunes del hogar, en ocasiones ellas se sentían culpables si gastaban para sí mismas.

Asimismo, el control de las finanzas domésticas ha estado asociado al poder dentro del hogar. Cuando ambos miembros de una pareja hacen un fondo común con sus ingresos y ambos pueden controlarlo, esos hogares se caracterizan por mayor igualdad entre cónyuges en otros aspectos, como la toma de decisiones, los "sacrificios" o privaciones, y el acceso a dinero para gastos personales. Vogler y Pahl (1994) reportaron que en hogares británicos de bajos ingresos, el control de las finanzas domésticas por parte de las mujeres, aunque les permitía mayor poder de decisión, no las protegía de experimentar privaciones, mientras que el control de las finanzas por parte de los hombres sí moderaba las privaciones de ellos, ya que tendían a reservarse algo de dinero para sus gastos personales. En los hogares de mayores ingresos, en general disminuía la desigualdad entre hombres y mujeres, especialmente cuando ambos compartían el control de un fondo común.

En el presente siglo, en distintos países prosiguieron los estudios en torno al manejo del dinero en las parejas desde el abordaje anglosajón. En el estudio de Elizabeth (2001) referente a la administración del dinero en parejas heterosexuales convivientes en Nueva Zelanda, se halló una tensión entre la equidad y la autonomía personal. La modalidad de cuentas separadas en parejas cohabitantes se utilizaba con el fin de evitar la dependencia financiera. Así, la pareja sentía que cada uno hacía una contribución igualitaria, manteniendo la autonomía individual. Sin embargo, esta modalidad generaba que el grado de autonomía de cada uno dependiera del monto de sus ingresos. Aunque el manejo del dinero por separado suela vincularse a una intención igualitaria, hace emerger nuevas asimetrías en la pareja, en particular cuando los ingresos son dispares.

Nyman y Reinikainen (2001), a partir de entrevistas en Suecia, uno de los países con mejores indicadores de igualdad de género, encontraron formas de perpetuación de la desigualdad en parejas en las que ambos tienen trabajo remunerado. Aunque no haya desigualdad en el ingreso que aportan al hogar, la división de responsabilidades entre varones y mujeres 
termina haciendo que ellos se ocupen de los aspectos más generales de la economía familiar y controlen sutilmente las áreas de responsabilidad de ellas, los temas sujetos a negociación y los límites de gasto. Las mujeres gastan menos en sí mismas y tienden a subordinar sus necesidades a las de otros miembros de la familia. Estos resultados cuestionan la hipótesis de Blood y Wolfe (1960) — que postulaba que el cónyuge con más recursos (dinero, educación, profesión) tiene más poder en la toma de decisiones y en las negociaciones de pareja-, ya que, aunque los "recursos de poder" sean similares, resurgen disparidades en la toma de decisiones.

La investigación de Woolley (2003) en Ottawa, Canadá, reportó no haber hallado un sesgo sistemático a favor de los hombres o de las mujeres. Sí encontró que las personas de mayores ingresos, especialmente cuando se trata de esposas jóvenes, tienen más control del dinero en la pareja. También detectó que cuando hubo matrimonios anteriores - especialmente del varón - hay una menor propensión a utilizar el fondo común. También en Canadá, Phipps y Woolley (2008) hallaron que las mujeres son más proclives a gastar en el consumo de los hijos y no parecen interesarse tanto como los hombres en tomar el control de las finanzas familiares con el fin de ahorrar para el retiro o para dejar un testamento.

El estudio de Kenney (2006), en Estados Unidos, sobre parejas heterosexuales con hijos, observó que cuando la mujer no tiene ingresos o son bajos en comparación con su esposo, las formas de manejo del dinero hogareño tienden a reproducir o exacerbar la desigualdad en la pareja. Tanto el control de todo el dinero en común por parte del marido, como las cuentas separadas, refuerzan la inequidad. Incluso cuando ambos nominalmente tienen acceso a un fondo común, es más probable que ellos tengan el control real. La individualización no parece afectar la equidad cuando los ingresos de los miembros de la pareja son similares, pero sí cuando los ingresos de las mujeres son menores - lo que sucede generalmente porque ellas se dedican a tareas domésticas y de cuidado no remuneradas.

En España, autoras como Cea D’Ancona (2007) corroboran que prevalecen las decisiones conjuntas para los gastos, pero se preguntan en qué grado el hecho de que alguien tome o participe de las decisiones implica que detenta poder en la pareja. A partir de entrevistas 
cualitativas a parejas de doble ingreso en España, Dema Moreno (2006) examinó la persistencia de desigualdades de género y obstáculos a los que se enfrentan las parejas con ideales igualitarios, incluso con independencia de la cuantía del ingreso de las mujeres. Si bien — como habían mostrado Pahl y Vogler - la modalidad de administración del dinero está vinculada al grado de asimetría de poder en la pareja, Dema Moreno considera que la desigualdad depende sobre todo de la dinámica interna de funcionamiento dentro de cada modelo.

En Reino Unido, pese a que estudios cuantitativos de principios de siglo han reportado una proporción importante de parejas en las que sería la mujer quien tiene el manejo y la "última palabra" en decisiones financieras, Bennett, Henau y Sung (2010) relativizan ese hallazgo para los hogares de bajos ingresos, donde el "control" o el "poder de decisión financiero" de la mujer es entendido como administrar el dinero cotidiano para que dure lo necesario. Asimismo, decisiones importantes de gasto que toman las mujeres suelen beneficiar a otros miembros de la familia antes que a ellas.

En India, Singh y Bhandari (2012) estudiaron la administración del dinero en familias ampliadas a lo largo de las generaciones. Si bien encontraron algunos patrones similares a los occidentales, como una preponderancia sobre la administración conjunta o independiente (es decir, no exclusiva del varón) cuando las mujeres tienen ingresos más altos, habría una diferencia en los valores subyacentes. En las parejas indias el control conjunto del dinero no obedecería tanto a razones de equidad e independencia, sino al bienestar de la familia ampliada. Por otra parte, en regiones rurales de India se verificó que el acceso de las mujeres al dinero facilita su capacidad de decisión sobre métodos de planificación familiar, independientemente del grado de tradicionalismo de las normas culturales (Reed, Donta, Dasgupta, Ghule, Battala, Nair y Raj, 2016).

Actualmente, en Europa Occidental se ha constatado que, en el manejo del dinero doméstico, el sistema de cuentas individuales — principalmente - y el de fondo común —en menor medida-, están asociados a valores de igualdad de género, frente al sistema tradicional del marido proveedor del hogar que maneja el dinero - ya sea de manera directa o por medio 
del "subsidio" a la esposa para los gastos comunes cotidianos. Çineli (2020), a partir de datos del ISSP de 2012 para varios países europeos, corrobora que los sistemas de administración conjunta y de cuentas separadas están más asociados a valores de género igualitarios, así como a ingresos y a edades similares entre los miembros de la pareja. El sistema de cuentas separadas es el que presenta la asociación más intensa con valores igualitarios.

En suma, las investigaciones acerca de la administración del dinero entre los miembros de parejas heterosexuales se desarrollaron especialmente en la sociología anglosajona desde las últimas décadas del siglo pasado. Las inquietudes comunes versaron sobre el grado y las formas de persistencia de las desigualdades de género en los hogares de dos proveedores. Las modalidades principales de administración del dinero son: único administrador de todo el dinero, fondo común con acceso de ambos y cuentas separadas individuales. La categoría de único administrador es la más tradicional: incluye el sistema de "subsidio" del proveedor que delega los gastos cotidianos por constituir una especie de tarea doméstica. Las variantes de fondo común y de cuentas separadas serían en teoría más modernas e igualitarias, pero no garantizan la equidad de género.

\section{Abordajes desde América Latina y Argentina}

En América Latina, los estudios ligados al tema han ofrecido enfoques más integradores. A menudo vinculan los conflictos de género en torno al dinero con dinámicas familiares y desigualdades de distinto tipo, en relación con el mercado y el Estado. Las problemáticas teóricas de las familias exhibieron múltiples aristas (Jelin, 2020; Seid, 2015; Gómez Rojas y Riveiro, 2014) y la cuestión de la autonomía de las mujeres ha sido uno de los denominadores comunes (García, 2003; Batthyány, 2008).

En México, Brígida García y Orlandina de Oliveira han hecho importantes aportes, como el análisis de la Encuesta sobre Dinámicas Familiares, que llevaron a cabo en la Ciudad de México y Monterrey a fines del siglo pasado. La toma de decisiones respecto del dinero y otras dimensiones del poder doméstico son vinculados con los aspectos sociodemográficos y la división intrafamiliar del trabajo remunerado y no remunerado. Por ejemplo, describieron 
la dinámica familiar de las mujeres jefas de hogar, corroborando que gozan de mayor poder de decisión dentro del hogar que las mujeres que ocupan el lugar de "esposas" de un jefe de hogar y, en lo que respecta al dinero, no sólo para los gastos reproductivos, sino también en la planeación a largo plazo (García y de Oliveira, 2005). Más recientemente, el estudio de Zazueta y Sandoval (2013) describe las concepciones de género y los conflictos en parejas heterosexuales en condiciones de pobreza en Sonora (México). Dentro de un marco de concepciones tradicionales de género que prevalecen en esta población, tienen lugar algunos cambios, como la participación femenina en el trabajo extradoméstico, pero persisten diferencias de género en el significado atribuido al dinero, como el hecho de que las mujeres lo vinculen "con principios negativos como la avaricia y con comportamientos individualistas, machistas o antisociales generados por la abundancia" (p. 107).

En Argentina, los estudios más conocidos en torno a dinero y género provinieron de la psicología. Entre las contribuciones más destacadas, pueden mencionarse los libros El sexo oculto del dinero: formas de la dependencia femenina (1986) y El dinero en la pareja, de la psicóloga Clara Coria (1989). A partir de registros producidos en grupos de reflexión de mujeres y hombres con distinto poder adquisitivo, Coria describió y conceptualizó desde la psicología las relaciones de poder entre varones y mujeres en lo que respecta al dinero. Así, puso en evidencia los mecanismos psíquicos que contribuían con la dependencia femenina en las parejas de fines del siglo pasado. Las asimetrías de poder se expresaban en el control masculino del dinero, significado como potencia sexual, mientras que las mujeres tendían a experimentar culpa por no estar socialmente legitimadas para administrar su propio dinero más allá de la "caja chica" doméstica. Por otra parte, y más recientemente, entre los aportes sociológicos argentinos en torno al dinero, se destacan los de Ariel Wilkis, algunos de los cuales abordaron las circulaciones monetarias, en sectores populares, en relación con roles de género (Wilkis y Partenio, 2010).

Para contextualizar el análisis que se presentará a continuación, téngase presente que la transición entre el modelo de familia de proveedor único y el de dos proveedores cobró fuerza a partir de la década de 1980 en Argentina. A menudo, las crisis económicas, el deterioro de los salarios reales y las medidas de ajuste indujeron a que más mujeres concurrieran y 
permanecieran en el mercado laboral. Además, "la postergación del matrimonio y la reducción del tamaño de la familia hicieron lo suyo en el mismo sentido" (Wainerman, 2003, p. 59).

\section{Metodología}

Nuestra investigación exploratoria de modalidades de administración del dinero en las parejas argentinas, cuyos resultados se presentarán a continuación, se basó en información cuantitativa y cualitativa. Como fuente cuantitativa se recurrió a la base de datos argentina de la Encuesta sobre Familia y Roles de Género del ISSP de 2012. El relevamiento en el país ${ }^{1}$ se llevó a cabo entre 2012 y 2013. Se efectuó un muestreo probabilístico polietápico que comprendió a 977 individuos, de los cuales 508 vivían en pareja. Por tratarse de un muestreo probabilístico, estos 508 casos, ponderados mediante el factor de expansión incluido en la base de datos, pueden suponerse estadísticamente representativos de las personas mayores de 18 años que viven en pareja en Argentina. Nuestro interés por esta fuente de información se debe a que, hasta donde sabemos, es la única encuesta de cobertura nacional que incluyó una pregunta específica respecto de la modalidad de administración del dinero en el hogar. Las alternativas de respuesta en el cuestionario eran: "Yo manejo todo el dinero y le doy a mi pareja su parte", "Mi pareja maneja todo el dinero y me da mi parte", "Ponemos el dinero en un fondo común y cada uno retira según lo que necesite", "Ponemos parte del dinero en un fondo común y mantenemos separado el resto" y, "Cada uno mantiene su dinero por separado”. En el procesamiento se recategorizaron según sexo las dos primeras respuestas.

Como fuente cualitativa se recurrió a 60 entrevistas semiestructuradas realizadas en el marco de dos proyectos de investigación ${ }^{2}$ entre los años 2010 y 2015, dirigidos por Gabriela Gómez Rojas, que versaban en torno a comportamientos de clase de las parejas y desigualdades de género en tareas domésticas y tiempo libre. El principal criterio de selección remitió a la

1 En Argentina, estuvo a cargo del Centro de Estudios de Opinión Pública del Instituto Gino Germani (Universidad de Buenos Aires), bajo la dirección de Jorge Raúl Jorrat.

2 Se trata de los proyectos UBACyT titulados "Heterogeneidad de clase social: profundizando los comportamientos de clase de las parejas" (2010-2012) y "Articulaciones entre clase, género, actividades domésticas y uso del tiempo libre" (2012-2015). 
posición de clase de cada miembro de la pareja, a modo de contar con mujeres y hombres de distintas clases sociales, que estuvieran en pareja con alguien de su misma clase (homogamia) o de otra (heterogamia). Las entrevistas resaltaron información laboral, educativa, familiar y de estilos de vida de varones y mujeres de distintas clases sociales en Buenos Aires y Mendoza. Si bien no era un tema principal, en la guía de pautas se incluyó una pregunta tocante al manejo del dinero en la pareja.

\section{Panorama general acerca del manejo del dinero en los hogares argentinos}

Como primera aproximación a la cuestión del manejo del dinero en el hogar se analizó la información de las personas viviendo en pareja de la muestra argentina del ISSP. Ante la pregunta: “¿Cómo organizan usted y su cónyuge o pareja los ingresos que uno o ambos perciben?", 43\% respondió que ponen el dinero en un fondo común y cada uno retira según lo que necesite (fondo común), 38\% respondió que uno de los dos maneja todo el dinero y le da al otro su parte (único administrador) y $19 \%$ que mantienen todo o una parte del dinero por separado (cuentas separadas). El 38\% correspondiente a único administrador es la suma de $16 \%$ en que el hombre administra y $22 \%$ en que administra la mujer. El $19 \%$ de los que mantienen dinero por separado se compone de $10 \%$ que administra totalmente por separado y $9 \%$ que pone parte del dinero en un fondo común y mantiene separado el resto.

Si se observan los ingresos familiares dentro de cada variante de manejo del dinero, en la de único administrador y en la de cuentas separadas los ingresos son menores (ver Gráfico 1). En cambio, en la subpoblación que usa el fondo común y, especialmente, en la subpoblación que pone en común una parte de los ingresos y mantiene otra parte por separado, la mediana de ingresos y el resto de las medidas de posición son sensiblemente mayores. Puede presumirse que el monto de ingresos disponibles condiciona la preferencia por una u otra modalidad de administración. Cuando hay mayores ingresos, alcanza para que haya fondo común e incluso para que además cada uno tenga su propio dinero. Cuando los ingresos son menores, la escasez parece imponer la necesidad de unificar el mando para administrar los gastos. 
Gráfico 1. Medidas de posición del ingreso del hogar en pesos argentinos (2013) según modalidad de manejo del dinero ${ }^{3}$

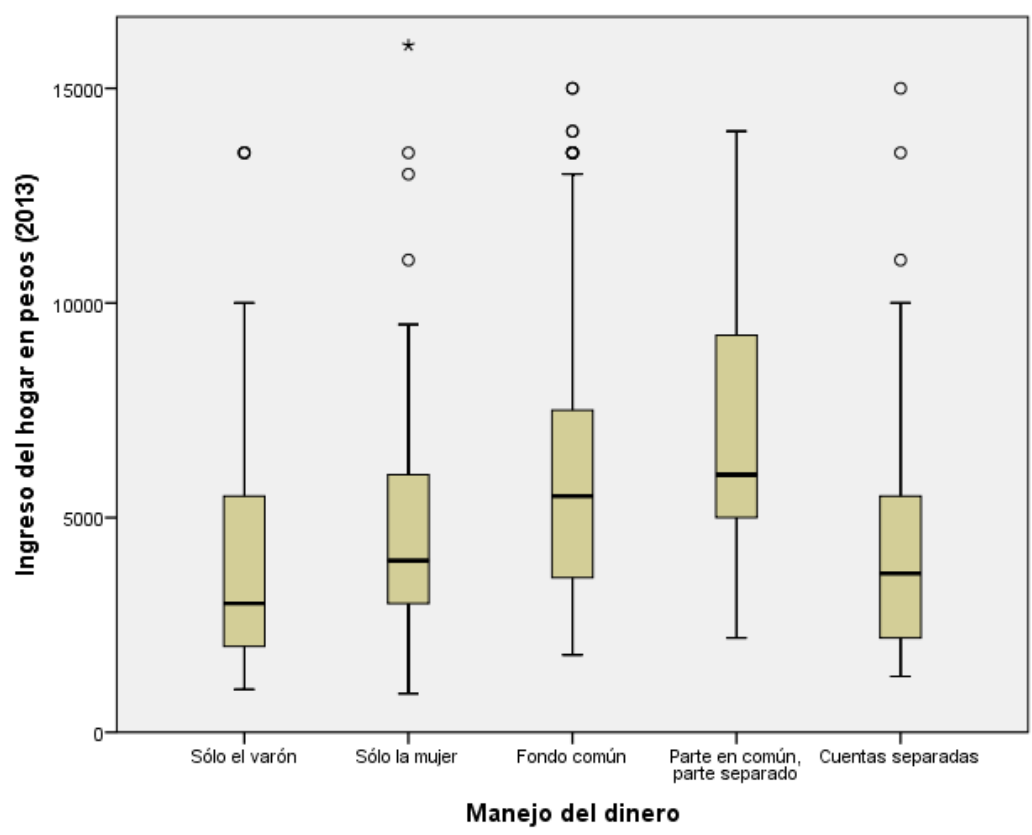

El monto de los ingresos del hogar depende de si hay uno o más aportantes y de las cuantías de los aportes. Más allá de los ingresos, para obtener una caracterización general acerca de qué condiciones propician unas u otras modalidades de administración del dinero, se analizaron éstas en distintas subpoblaciones: según quién trabaja de manera remunerada, según el principal aportante de ingresos y según el nivel educativo.

En el Gráfico 2 puede observarse que cuando sólo el varón trabaja de manera remunerada en la pareja, en $40 \%$ de los casos administra el dinero la mujer y en $25 \%$ el propio varón. Sumando ambas, en 65\% de las parejas en las que solo él trabaja en el mercado, se impone la modalidad de un único administrador del dinero. Esta situación contrasta con la distribución general —allí las variantes de administrador único eran 38\% del total—, y especialmente, con la situación en la que ambos miembros de la pareja trabajan, dentro de la cual la categoría de administrador único suma apenas 22\%. Cuando trabajan ambos, ganan

\footnotetext{
${ }^{3}$ La información de todas las gráficas tiene como base: 508 encuestados de Argentina que viven en pareja. Y se elaboró con sustento en el ISSP 2012.
} 
mucho terreno las variantes de fondo común y de cuentas separadas. Si bien la submuestra de parejas en las que solamente trabaja la mujer es muy reducida (menos de 20 casos), su distribución de modalidades de manejo del dinero en principio se asemeja más a la que tiene lugar cuando trabajan ambos que a la que se presenta cuando trabaja sólo el varón.

\section{Gráfico 2. Modalidad de manejo del dinero según quién trabaja de manera remunerada}

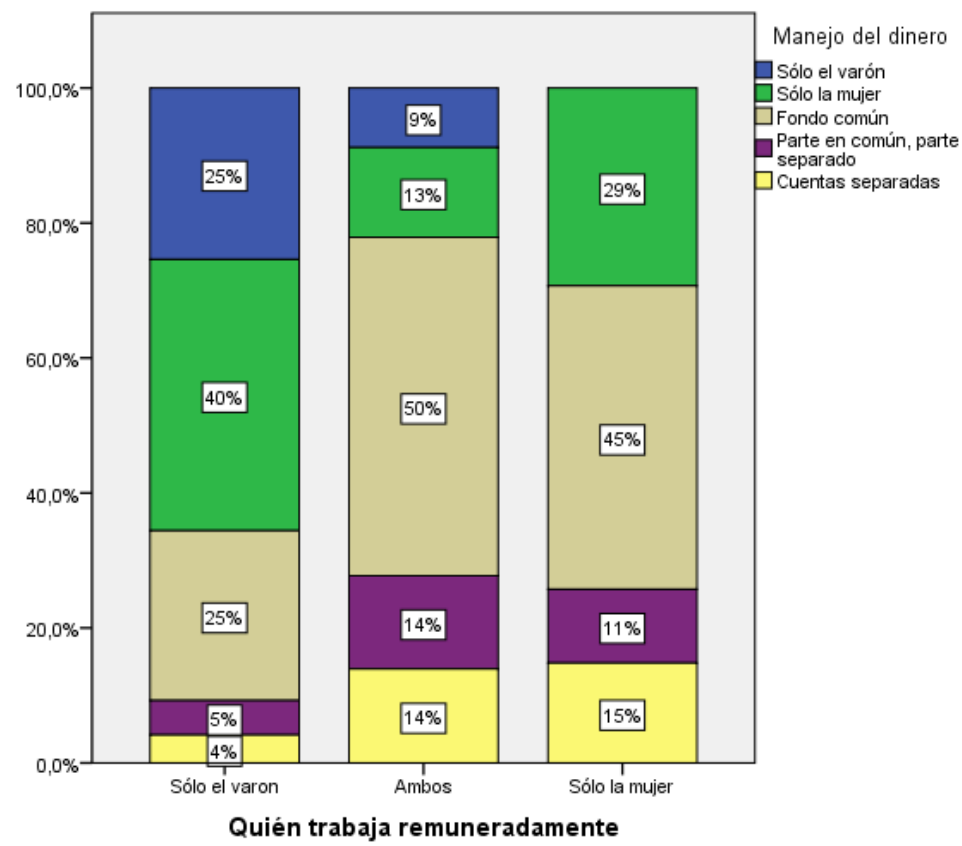

Otra posibilidad para comparar los modos de administración del dinero es observar qué ocurre cuando varía el aportante de ingresos. En el Gráfico 3 se agruparon en una misma categoría (respectivamente, "El varón” y "La mujer") los casos de un único aportante de ingresos con los casos en los que un miembro de la pareja aporta más que otro. Cuando el principal (o único) aportante de ingresos es el hombre, las modalidades de único administrador (sea él o la mujer) alcanzan casi la mitad de los casos. En contraste, cuando aportan ambos por igual, las variantes de único administrador apenas conforman $14 \%$ del subtotal.

Tanto este gráfico como el anterior evidencian que cuando el varón es quien aporta dinero al hogar, se tornan más probables las variantes de único administrador, sea que el hombre delegue el rol en su pareja o que administre él mismo. Cuando ambos aportan ingresos, 
especialmente cuando lo hacen en cuantías similares, el fondo común supera la mitad de los casos y las cuentas separadas suman casi un tercio.

Gráfico 3. Modalidad de manejo de dinero según principal aportante de ingresos del hogar

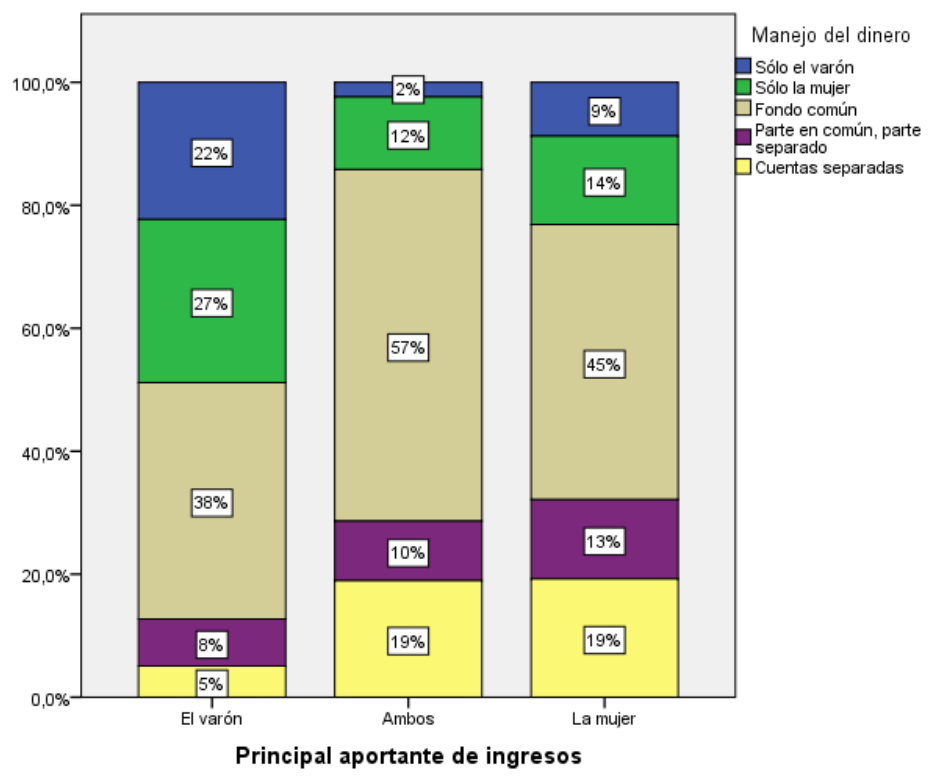

El nivel educativo (Gráfico 4) puede vincularse a la forma de administración del dinero mediante dos vías: las desigualdades de ingresos según la educación, y las distintas pautas culturales en las poblaciones de distinto nivel educativo. En el siguiente gráfico se observa que, a mayor nivel educativo, disminuye la proporción de los que optan por un único administrador del dinero, y aumenta la administración mediante fondo común y cuentas separadas. 


\section{Gráfico 4. Modalidad de manejo del dinero según el nivel educativo*}

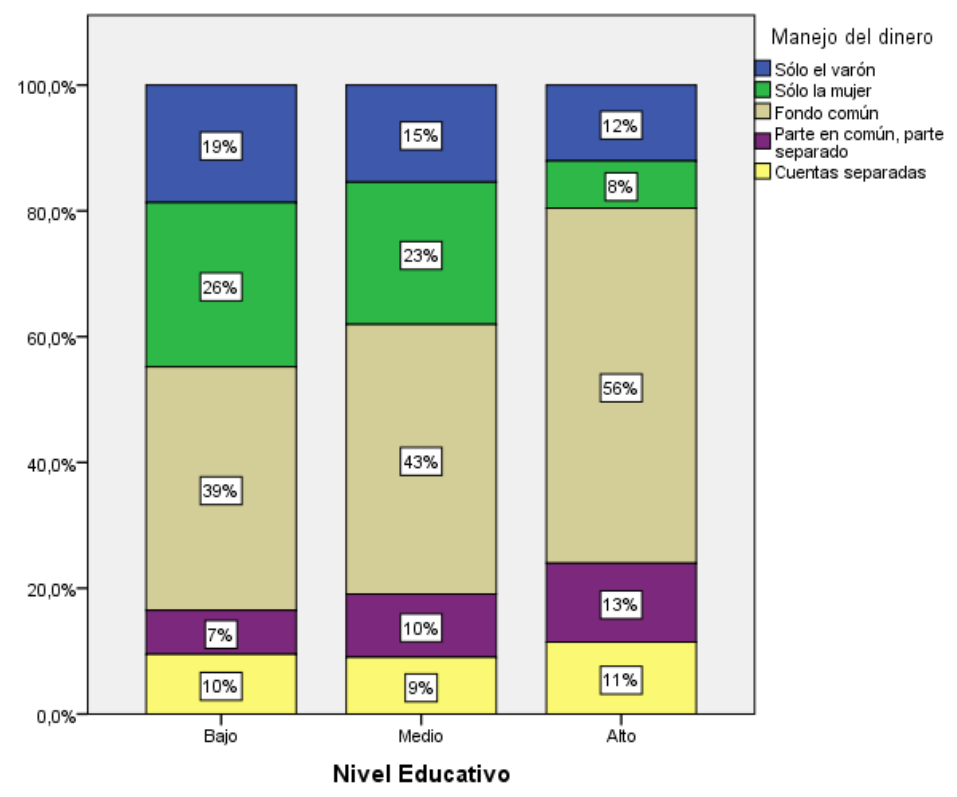

*El nivel educativo se elaboró a partir de la cantidad de años de estudio: hasta 7 años, bajo; de 7 a 12 años, medio; más de 12, alto.

Como última variable independiente para considerar, a continuación, se presentan las formas de administración del dinero (Gráfico 5) según un indicador de posición ideológica respecto a la igualdad de género: el grado de acuerdo con la frase: "La tarea del hombre es ganar dinero, la de la mujer es cuidar del hogar y la familia". Cuando se está en desacuerdo con la frase, se reduce la proporción de las modalidades de único administrador, mientras que aumenta el porcentaje de los que se organizan mediante cuentas separadas y, sobre todo, la combinación de fondo común y cuentas separadas. 


\section{Gráfico 5. Modalidad de manejo del dinero según el grado de acuerdo con que la tarea del hombre es ganar dinero y la de la mujer cuidar del hogar y la familia}

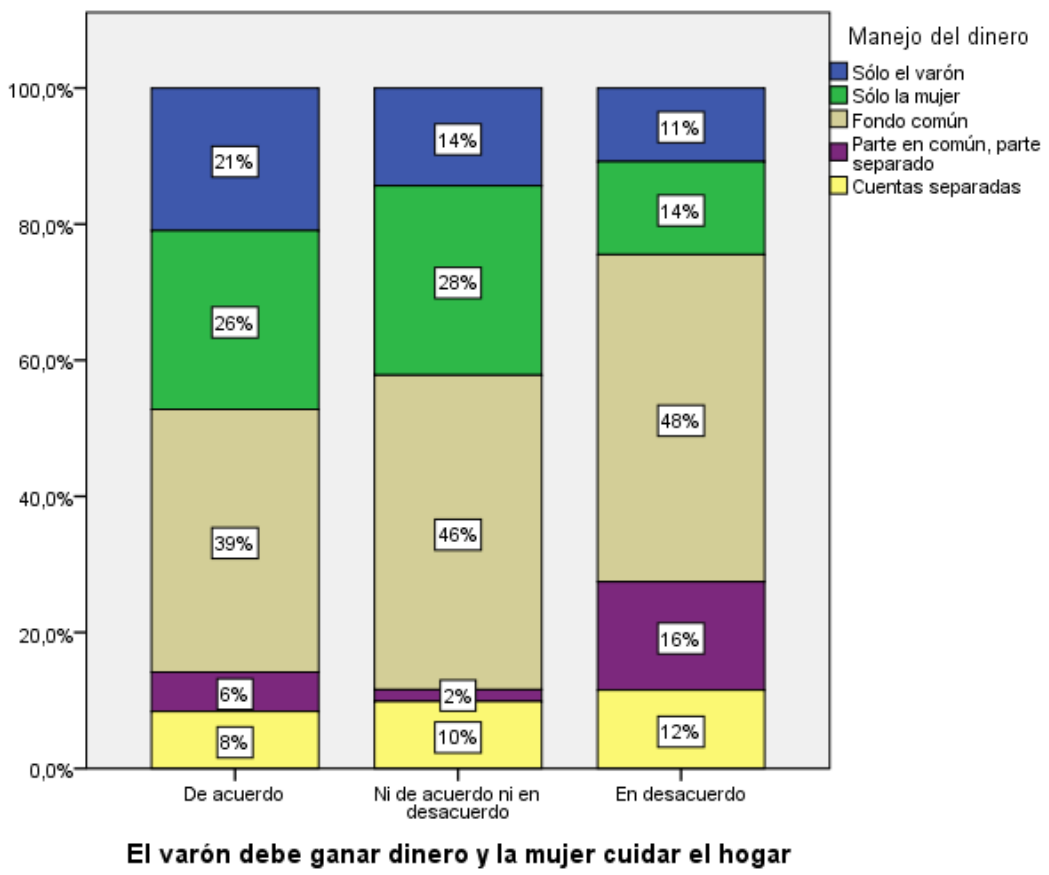

Por otra parte, se examinó la asociación entre la modalidad de administración del dinero y dos indicadores de poder en el ámbito doméstico: quién toma (o tomaba) usualmente las decisiones acerca de cómo criar a los hijos, y quién tiene la "última palabra" para elegir actividades compartidas de fin de semana. Se halló independencia estadística entre las decisiones de la crianza y la de manejo del dinero. Puede hipotetizarse que, si la categoría de único administrador del dinero se asocia a una concepción tradicional del hombre proveedor, en estas situaciones el rol del varón en la crianza de los hijos puede consistir tanto en intervenir en carácter de jefe de familia, como en no responsabilizarse y delegar a la mujer las decisiones de la crianza de los hijos, al asumir una división tradicional de esferas de poder.

En cuanto a la "última palabra" (Gráfico 6) para las actividades compartidas de ocio, la asociación con el manejo del dinero es estadísticamente significativa. Si bien para cualquier modalidad de administración del dinero predominan las decisiones compartidas, las diferencias son sustantivas. Cuando hay un único administrador, es menor la proporción de los que afirman que ambos miembros de la pareja tienen la misma autoridad para decidir qué hacer o dónde salir el fin de semana. Cuando quien maneja el dinero es la mujer, en 31\% de los casos es ella quien tiene la "última palabra" (el porcentaje más alto de decisión 
unipersonal). Cuando organizan el dinero en un fondo común, y especialmente cuando combinan fondo común con dinero individual, las decisiones conjuntas para el ocio llegan a porcentajes muy altos ( 84 y 90\%). La modalidad de cuentas separadas no se diferencia, en su covariación con las decisiones de ocio, de la modalidad en la que el varón es el único administrador. En términos generales, las mujeres parecen tener un poder de decisión algo mayor que los hombres, sea por una concepción tradicional que les atribuye a ellas la decisión de estos asuntos, o por los efectos individualizantes de la organización mediante cuentas separadas.

Gráfico 6. ¿Quién tiene la última palabra en actividades compartidas de fin de semana?, según la modalidad de manejo del dinero

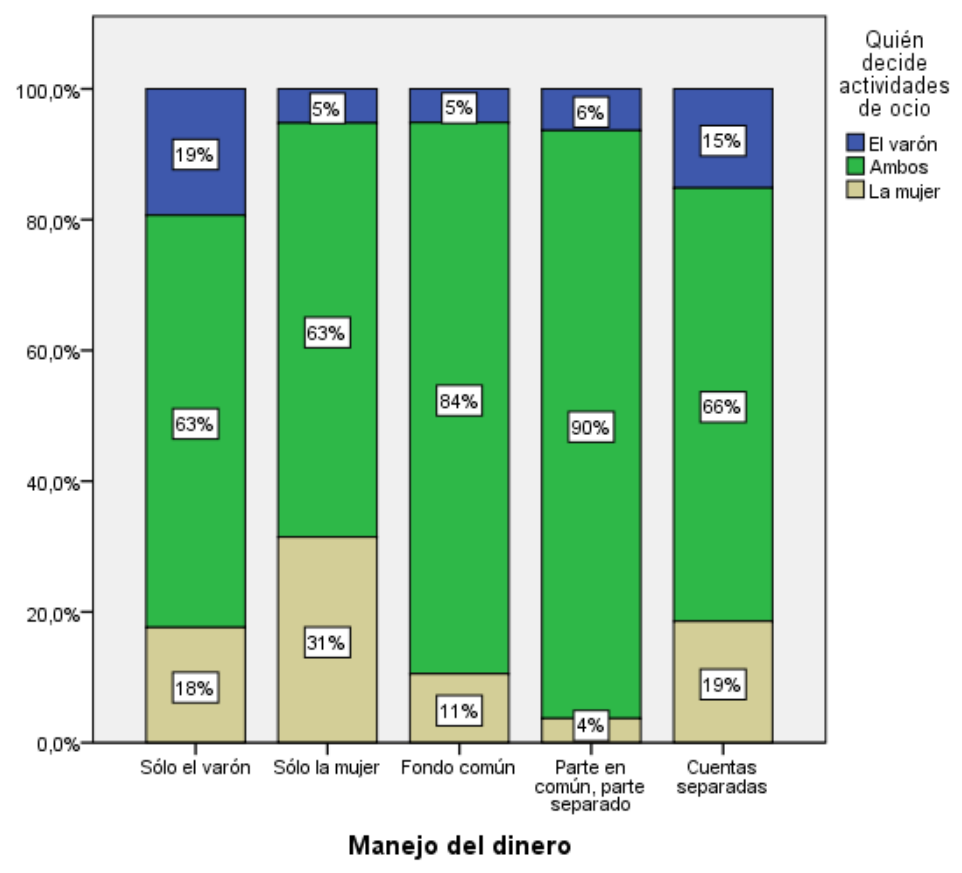

En suma, la aproximación cuantitativa sugiere que, al igual que en otros países, en Argentina también las modalidades de único administrador del dinero están más asociadas al varón proveedor y a concepciones de género tradicionales, mientras que las de fondo común y cuentas separadas se vinculan con ideas más igualitarias. Dentro de estas últimas, la que combina fondo común y dinero individual se destacó casi en todos los gráficos: se halló asociada a dos proveedores, mayores ingresos, mayor educación y nociones de género más igualitarias. 


\section{Indicios cualitativos}

La pregunta por el manejo del dinero doméstico, cuando se hace en el marco de una entrevista cualitativa, permite acceder a información más detallada acerca de prácticas y significados. Sin embargo, no es un tema sencillo de abordar, y las respuestas no siempre son más ricas que las que se obtendrían mediante un cuestionario con alternativas de respuesta prefijadas. Al preguntar simplemente cómo manejan el dinero en el hogar, buena parte de las respuestas son imprecisas. Respuestas típicas como "ponemos todo junto" pueden parecer claras, pero omiten si alguien tiene el dinero en su poder, si otros deben pedirlo y cómo se deciden los gastos. En algunos casos en que fue posible seguir preguntando, se halló que la administración del dinero no era en realidad mediante fondo común, sino que estaba a cargo de una sola persona. En otros casos, cierta incomodidad impidió seguir preguntando, ya que el manejo del dinero puede ser considerado un asunto íntimo que no corresponde divulgar. Una de las entrevistadas, esposa de un policía, prefirió dejar de responder sobre el tema:

— ¿Cómo organizan usted y su esposo los ingresos que ambos perciben?

— No, yo manejo todo el dinero.

- ¿Qué gastos del hogar cubre usted con sus ingresos y qué gastos cubre su marido?

— Todo para todo.

— ¿Alguno gana más?

— Más o menos lo mismo.

- ¿Alguno cobra a través del banco y otro en efectivo?

- No voy a responder, no debería responder, porque mirá con la inseguridad que hay si después nos pasa algo. Mi marido me cuenta de los casos, así que no... qué sé yo, pasan tantas cosas, roban a cada rato, uno tiene desconfianza... (Norma, peluquera, Mendoza).

Si bien la mayoría de las personas entrevistadas no expresa inconvenientes para responder, no puede descartarse que algunos den respuestas deliberadamente vagas, sea porque perciben 
que no es seguro revelar esa información o porque consideran que podría ser mal vista la manera en que se maneja su familia.

En términos generales, los hallazgos cualitativos concuerdan con la información cuantitativa disponible. En todas las parejas en que ambos tienen ingresos, se usa el dinero de ambos para los gastos familiares, es decir, en ningún caso la cobertura de todos los gastos familiares estaba a cargo de un solo miembro de la pareja. Independientemente de la modalidad de manejo del dinero, las mujeres que tienen ingresos similares o superiores que sus esposos perciben que ello les permite mayor autonomía y poder de negociación y decisión en la pareja:

— Si yo no trabajara sería mucho menos feliz.

— ¿En qué sentido?

— Y... me ajustaría a lo que él me diga, me tendría que atener a eso. En cambio, yo trabajo y trabajo tanto como él, tengo mi derecho, yo me siento segura porque tengo mi plata en el bolsillo, porque me lo gané honradamente trabajando como burra, ¿entendés?, cosa que la mujer de antes no. Tenía que ser sumisa, hasta el tipo capaz le podía dar un cachetazo, qué sé yo, estaba acostumbrado a maltratarla (María, tesorera en clínica, esposo encargado fabril, Buenos Aires).

La modalidad de administrador único, más habitual en los hogares con un solo proveedor y menores ingresos, puede ser adoptada por algunas parejas de doble ingreso cuando perciben que uno de los miembros tiende a malgastar el dinero. Una de las entrevistadas relata que el marido le pidió que ella le administre su dinero:

Lo único que puede causar conflicto es "me voy a jugar". Y va dos veces por semana o tres, pero después nada, el resto no, tampoco voy a pretender no vayas a la cancha [...] él no tiene capacidad de ahorro. Salió de él, porque a mí nunca se me hubiera ocurrido que yo le administre su plata. Él solo me dijo en un determinado momento vos 
manejame la plata. Obvio que es de los dos, pero se trata de un control, porque yo tengo un poco más de control (Romina, profesora, esposo camillero, Buenos Aires).

De acuerdo con la información cuantitativa, cuando hay dos ingresos, predomina el fondo común y, en segundo lugar, las cuentas separadas. Las entrevistas en profundidad aportaron algunos pormenores de las formas concretas de organizar el manejo del dinero, permitieron identificar algunas variantes dentro de las modalidades y reconocer combinaciones entre ellas. Muchas parejas administran sus ingresos de un modo singular, que no se reduce a fondo común o dinero individual, si bien estas modalidades podrían tomarse como extremos de un continuum.

Las personas entrevistadas que afirman compartir el dinero con su pareja lo hacen de distintos modos. Algunos conciben al dinero como compartido, pero lo guardan por separado:

Ah, somos muy desordenados, te aviso. No somos ejemplo de orden nosotros. El que tiene primero la plata paga lo que se vence primero, es así. Todo, o sea, compartimos el dinero. No es que este es mi dinero y este es tu dinero, es nuestro dinero. Por ejemplo, hay que pagar la luz y se vence mañana, yo no tengo plata y él tiene: va y paga. Tanto es así que a veces a mí me sobra dinero del sueldo y otras veces no. Y bueno, pero no importa porque si yo necesito y él tiene me lo da, y si él necesita y yo tengo se lo doy (Patricia, profesora, esposo peluquero, Buenos Aires).

No es frecuente que simplemente se reúna la totalidad de ambos ingresos y se considere el conjunto como dinero de ambos, sin más. Aunque los flujos de dinero se mezclen sin haber calculado con exactitud cuánto aportó cada uno, no deja de haber una idea aproximada. Especialmente cuando los ingresos son similares, suele haber una búsqueda deliberada de que los esfuerzos estén repartidos equitativamente: 
- Lo primero que hacemos es pagar boletas, tarjetas, todo, y después lo que queda se pone en un fondo común y de ahí más que nada lo manejo yo.

- ¿Qué gastos del hogar cubre usted con sus ingresos y qué gastos cubre su marido?

- Y, generalmente son repartidos, yo pago los impuestos y él paga tarjetas de crédito, algún préstamo, tratamos de equiparar los costos (Fabiana, maestra, esposo vigilante, Mendoza).

Así, un fondo común puede recoger una parte o la totalidad de los ingresos, puede ser un modo general de administración o bien crearse para finalidades específicas (irse de vacaciones, comprar un electrodoméstico) y, fundamentalmente, su adopción puede estar guiada por distintas lógicas, inserta en distintos entramados de significados acerca del cuerpo familiar y de las obligaciones recíprocas de sus miembros.

También la modalidad de cuentas separadas presenta variaciones. Algunas parejas que manejan el dinero por separado y no lo mezclan se administran teniendo en cuenta los ingresos de ambos y eventualmente uno puede acceder al dinero del otro:

Yo cobro y digo: "Yo hice esto, pude comprar esto y pude pagar, y esto me quedó". Y si necesita saca y si no, no. Guardar no, porque es difícil, pero siempre fue igual, digamos que los dos sabemos dónde está la plata si la necesitamos, cuánto tenemos y cuánto vamos a gastar [...] por ejemplo, yo me ocupo de pagarle a él la obra social, que para mí en este momento es más que importante porque él ya está grande y tiene algunos problemas de salud, entonces no quiero que pierda tiempo y haga todo rápido, entonces yo me ocupo de pagársela, también le pago a mi hija y a mi nieta y él se ocupa de otras cosas (María, tesorera en clínica, esposo encargado fabril, Buenos Aires). 
En las parejas de cuentas separadas es habitual que cada miembro se comprometa a hacerse cargo de gastos específicos. Estos compromisos pueden derivarse de estereotipos de género, es decir, que los ingresos del hombre se destinen a gastos fijos $u$ ordinarios para el mantenimiento del hogar, mientras que los ingresos de la mujer se usen para gastos ocasionales. Sin embargo, las entrevistadas no solían asociar tipo de gasto del hogar (fijo u ocasional) y sexo del pagador. Incluso es habitual la relación inversa a la que supondría una concepción de género tradicional del varón proveedor.

Parecen ser muy comunes los criterios pragmáticos, derivados de necesidades familiares o de prioridades individuales. En los discursos de las mujeres acerca de quién se hace cargo de los distintos gastos del hogar no predominan las referencias a lo que "corresponde" o es “justo”, que tal o cual miembro en particular se haga cargo. Más bien, cuando se considera a alguien responsable de cubrir determinado gasto, suele justificarse esa división por motivos de organización o comodidad.

En otros casos, por el contrario, la organización es más espontánea y variable. Típicamente para los gastos pequeños no está predeterminado quién pagará cada gasto. Consideran indistinto quién pone su plata en cada ocasión, confiando en que, a la larga, los aportes de ambos tienden a equipararse:

No, cada uno maneja su dinero y vamos gastando cada uno más o menos lo mismo, a veces tenemos un fondo común, pero por lo general vamos comprando entre los dos, es totalmente independiente, a veces hacemos un fondo común para los gastos, pero muy pocas veces, va uno al supermercado o va el otro, es así (Verónica, abogada, esposo encuestador, Buenos Aires).

[...] ahora nuestro alquiler es cero y sólo pagamos ciento treinta pesos de expensas. Lo pago yo, a menos que justo no tenga plata y se lo tenga que pedir. Pero, en general, yo soy la que tiene que pedirle si necesita algo, porque yo agarro las cosas y voy y las pago. Si va al supermercado las paga él, y si no, las pago yo. La verdad es que no hay mucho recuento de eso. 
Si no tengo, te lo pido, y si no, lo paga él (Carla, politóloga, esposo dueño de taller mecánico, Buenos Aires).

Las entrevistadas admitieron en pocas ocasiones haber tenido conflictos por el dinero dentro del hogar, se les pregunte o no. Cuando se le preguntó a una de las entrevistadas si alguna vez hubo problemas con su pareja por el manejo del dinero, respondió inmediatamente que no, pero a continuación se explayó acerca de importantes tensiones. Carla (politóloga) argumenta que su marido (dueño de un taller mecánico) pretendía seguir la costumbre de su familia, en la que el padre era el proveedor de ingresos y decidía las erogaciones. Carla sostiene que ella notaba una asimetría de poder en su pareja, puesto que su marido podía disponer del ingreso de ella, pero ella no tenía acceso al dinero de él:

Conflicto no, pero sí Pablo tiene una forma de manejarse con la plata muy distinta a mí, pero porque Pablo viene de una familia donde el padre es el que ganaba la plata y el padre decía para qué hay que usarla. Entonces al principio tenía como esta cosa de querer controlar hasta lo que yo ganaba, y a mí me costó muchas peleas separarlo, o sea, yo me voy a ocupar de algunas cosas, no te metas en las mías, porque él no da lugar a que yo me meta en las suyas, en su vida, pero él sí se inmiscuía mucho en la mía.

Lo que relata Carla puede interpretarse en términos de poder de negociación en la pareja cuando la mujer es de una clase social superior a la del hombre. Los conflictos en torno al manejo del dinero condujeron a la decisión de administrar de forma independiente sus ingresos:

Pablo vive haciendo negocios, pone de sus cosas y de las de los demás si lo dejás, pero él no te pregunta qué opinas vos, o sea, él hace y deshace, entonces bueno, yo sí crecí con los dos padres que sí decidían, aunque en mi casa decide más mi papá porque es él el que genera más la plata, pero sí importa lo que diga mi mamá, entonces tuvimos mucho roce con eso hasta que lo logramos separar. Si querés hacer tus negocios, hacelos, pero 
hacelos con tu plata y tu vida y no me metas, mi plata es mi plata, yo la uso para las cosas de la casa y qué sé yo, pero no para tus cosas [...]. No era la plata, a mí lo que me molestaba es la actitud como de desvalorizarme en un punto, como diciendo tipo yo soy el más vivo, en algún punto desvalorizar el trabajo del otro, porque pareciera que él era el que se esforzaba por la plata y qué sé yo y uno nada, le caían los sueldos de arriba.

En uno de los motivos del conflicto que relata nuestra entrevistada, referido a las diferentes concepciones respecto del manejo del dinero, se articulan estereotipos de género con características particulares de los empleos de cada uno: ella tiene una remuneración mensual fija y él tiene ingresos irregulares que pueden depender de operaciones de compraventa:

Pablo tiene como mucho esta cosa de hacer negocios que compra y vende, y qué sé yo, entonces la plata de él aparece y desaparece y para él hablar de plata es hablar de diez mil pesos y para mi hablar de plata es hablar de mil, ¿entendés? Cuando a mí me falta plata, me faltan trescientos pesos; cuando a él le falta, le faltan ocho mil.

Algunos varones entrevistados relataron conflictos por querer ser quienes sustenten con su propio ingreso algún determinado gasto. La cuestión de género puede aparecer vinculada al manejo del dinero de manera indirecta, mediante significados en torno al poder y la autosuficiencia. En este sentido, cabe resaltar que los conflictos domésticos en torno al dinero no son solamente aquellos en los que, como en el mercado, se disputa cuánto le corresponde recibir a cada uno. En las familias también revisten importancia las fricciones debidas a que alguno considera que está aportando menos de lo que debería al esfuerzo familiar:

— Ella trabajaba, [el manejo del dinero] era cada uno por su cuenta, pero tuvo un gran período en el que la despidieron y no consiguió trabajo. Igualmente, yo lo administraba por mi cuenta, yo hacía las compras, los pagos y demás, pero ahí lo manejaba yo, si ella necesitaba me pedía, pero tampoco se sentía muy cómoda, era motivo de discusión, cuánto... de 
cuánto disponíamos por día o por mes, pero bueno se manejó, nos manejamos así, ella dependiendo mucho de lo que yo le diera, también había un tema de que yo quería trabajar más. Ella se manejaba más con el efectivo, yo quería darle una extensión de la tarjeta y ella no quería, no sabía usarla.

— Decís que era motivo de discusión, ¿pero el conflicto cuál era?

- El conflicto era que ella dependía de lo que yo le diera o que ella me tenía que pedir plata a mí porque estaba desocupada.

— ¿Pero ella... el problema era porque te quería pedir más dinero?

- Era, por ahí pedir más o no me quería pedir (Renato, liquidador de sueldos, esposa empleada de comercio, Buenos Aires).

Cuando un miembro de la pareja se siente incómodo por aportar menos que el otro, el malestar puede interpretarse en términos de poder en el hogar: una desventaja en la posición en el mercado está afectando su poder simbólico en el campo doméstico.

Mientras todos los indicios apuntan a que la modalidad de administrador único está ligada a una concepción tradicional/patriarcal de la pareja, la de cuentas separadas en algunos discursos aparece vinculada a un grado de individualización incompatible con la vida en pareja:

- Totalmente independiente. Ni siquiera una cuenta bancaria juntos teníamos.

— ¿Cómo era el sistema?, "yo pago esto, vos pagas lo otro”, ¿o dividían la cosa a la mitad?

- Sí, más o menos. Cada cosa a la mitad. Hay cosas que pagaba uno y otras pagaba el otro, tampoco era tan estricto, pero sí, no había algo en común. Por eso me separé [risas] (Mercedes, arquitecta, expareja de la misma profesión, Buenos Aires). 
En suma, los arreglos de pareja respecto del manejo del dinero son variados, y a menudo flexibles y cambiantes. Muchas parejas no se ajustan a ninguna modalidad "pura", alternan responsabilidades de gastos, reservan una parte para ellos y aportan otra a un fondo común. Las variantes puras de administrador único y de cuentas separadas son los extremos entre los que se ubican la mayoría de los arreglos.

\section{Conclusiones}

De manera similar a otros países occidentales, en Argentina la modalidad de administrador único prevalece en los hogares de un sólo proveedor y está asociada a ideas de género más tradicionales, mientras que las de fondo común y de cuentas separadas prevalecen en los hogares de dos proveedores y se vinculan con nociones de género más igualitarias. Cuando solamente el varón aporta ingresos al hogar, dos tercios de las parejas designan un único administrador, lo que puede relacionarse a ideas de género tradicionales, tanto si el hombre controla todo el dinero, como si le da un "subsidio" a la mujer para los gastos comunes. Cuando ambos trabajan, en cambio, la modalidad de único administrador es minoritaria (menos de una cuarta parte de las parejas).

Dentro de las modalidades potencialmente más igualitarias, la de fondo común es la más habitual. Sin embargo, la que combina una parte en común y otra parte por separado, aunque numéricamente minoritaria, exhibió variaciones teóricamente relevantes: se halló asociada a dos proveedores, mayores ingresos, mayor educación y concepciones de género más igualitarias. Además, el análisis cualitativo sugirió que esta modalidad podría tener un peso mayor, ya que varias personas entrevistadas que afirmaban compartir el dinero, cuando se explayaban acerca del manejo cotidiano, en realidad mantenían buena parte del dinero por separado, pero lo concebían como compartido y cada uno tenía permitido el acceso al dinero en poder del otro. En las personas con empleos registrados que cobran mediante cuenta bancaria puede esperarse que esta modalidad sea muy habitual. También puede hipotetizarse que esta variante es el arreglo que minimiza la tensión, señalada en estudios previos, entre equidad y autonomía individual. 
El análisis cualitativo permitió visualizar una mayor diversidad y flexibilidad en los arreglos pragmáticos. Dentro de cada tipo de administración del dinero, las variantes son relevantes porque pueden tener distintas implicancias respecto a la igualdad de género y al poder en el hogar. Por ejemplo, cuando la mujer maneja el dinero, es muy distinto si lo hace en carácter de administradora del "subsidio" que el esposo otorga para los gastos comunes, que si lo hace porque la pareja considera que ella es la más responsable o menos propensa al dispendio. En el análisis cualitativo se evidenció también que no que no hay distinción tajante entre fondo común y cuentas separadas. El dinero puede ponerse todo junto incluso físicamente, pero calculando cuánto aporta cada uno. O bien el dinero puede mantenerse separado, pero con acceso automático de cada uno al dinero del otro toda vez que lo necesite.

El nivel de ingreso, el nivel educativo y la ocupación, analizados como proxys de clase social, sugirieron que, en términos generales, los hogares de posiciones de clase superiores tienden a arreglos más igualitarios. Además, la clase social individual del hombre y la mujer en una pareja tiene efectos en la forma de manejo del dinero y el poder en el hogar. Las mujeres de posición superior a su pareja manifestaron en las entrevistas sentirse empoderadas para contrarrestar el machismo en el hogar y resolver los conflictos de una manera equitativa.

Las tendencias analizadas se sitúan en procesos históricos. En la última década, tanto en Argentina como en el mundo occidental en general, tuvieron lugar rápidas transformaciones en las relaciones de género. En Argentina, por otra parte, la última década ha sido de estancamiento económico y decrecimiento de los ingresos de los hogares. Estas dos tendencias conjugadas sugieren que pueden haber variado los patrones de administración del dinero en las parejas, e invitan a futuras investigaciones respecto de las posibles transformaciones recientes y los perfiles de las generaciones más jóvenes.

\section{Referencias bibliográficas}

Batthyány, Karina. (2008). Pobreza y desigualdades sociales: Una visión desde el género. Papeles de población, 14(57), 193-207. 
Bennett, Fran; De Henau, Jerome y Sung, Sirin. (2010). Within-household inequalities across classes? Management and control of money. En Jacqueline Scott, Rosemary Crompton y Clare Lyonette (Eds.), Gender inequalities in the 21st century: New barriers and continuing constraints (pp. 215-241). Northampton: Edward Elgar Publishing.

Blood, Robert y Wolfe, Donald. (1960). Husbands and Wives: The Dynamics of Married Living. Illinois: Free Press.

Cea D’Ancona, Ángeles. (2007). La deriva del cambio familiar: hacia formas de convivencia más abiertas y democráticas. Madrid: CIS.

Çineli, Beyda. (2020). Money Management and Gender Equality: An Analysis of DualEarner Couples in Western Europe. Family Relations. Interdisciplinary Journal of Applied Family Science, 69(4). doi: https://doi.org/10.1111/fare.12465

Coria, Clara. (1986). El sexo oculto del dinero. Formas de la dependencia femenina. Buenos Aires: Grupo Editor Latinoamericano.

Coria, Clara. (1989). El dinero en la pareja. Algunas desnudeces sobre el poder. Buenos Aires: Grupo Editor Latinoamericano.

Dema Moreno, Sandra. (2006). Una pareja, dos salarios: el dinero y las relaciones de poder en las parejas de doble ingreso. Madrid: CIS.

Elizabeth, Vivienne. (2001). Managing Money, Managing Coupledom: a Critical Examination of Cohabitants' Money Management Practices. The Sociological Review, 49(3), 389-411. doi: https://doi.org/10.1111/1467-954X.00338 
García, Brígida. (2003). Empoderamiento y autonomía de las mujeres en la investigación sociodemográfica actual. Estudios demográficos y urbanos, 18(2) 221-253. doi: http://dx.doi.org/10.24201/edu.v18i2.1162

García, Brígida y De Oliveira, Orlandina. (2005). Mujeres jefas de hogar y su dinámica familiar. Papeles de población, 11(43), 29-51.

Gómez Rojas, Gabriela y Riveiro, Manuel. (2014). Hacia una mirada de género en los estudios de movilidad social: interrogantes teórico-metodológicos. Boletín Científico Sapiens Research, 4(1), 26-31.

Jelin, Elizabeth. (2020). Familia, un modelo para desarmar. En Elizabeth Jelin. Las Tramas del Tiempo. Familia, género, memorias, derechos y movimientos sociales (pp. 253278). Buenos Aires: CLACSO.

Kenney, Catherine. (2006). The Power of the Purse: Allocative Systems and Inequality in Couple Households. Gender \& Society, 20(3), 354-381. doi: https://doi.org/10.1177/0891243206286742

McRae, Susan. (1987). The Allocation of Money in Cross-Class Families. The Sociological Review, 35(1), 97-122. doi: https://doi.org/10.1111/j.1467-954X.1987.tb00005.x

Nyman, Charlott y Reeinikainen, Lasse. (2001). Bajo la aparente igualdad de género: El reparo del dinero en las familias suecas. Abaco: Revista de cultura y ciencias sociales, 29, 29-38.

Pahl, Jan. (1983). The Allocation of Money and the Structuring of Inequality within Marriage. The Sociological Review, 31(2), 237-262.

Pahl, Jan. (1990). Household Spending, Personal Spending and the Control of Money in Marriage. Sociology, 24(1), 119-138. 
Phipps, Shelley y Woolley, Frances. (2008). Control over money and the savings decisions of Canadian households. The Journal of Socio-Economics, 37(2), 592-611. doi: https://doi.org/10.1016/j.socec.2006.12.042

Reed, Elizabeth; Donta, Balaiah; Dasgupta, Anindita; Ghule, Mohan; Battala, Madhusudana; Nair, Saritha; Silverman, Jay; Jadhav, Arun; Palaye, Prajakta; Saggurti, Niranjan y Raj, Anita. (2016). Access to Money and Relation to Women's Use of Family Planning Methods among Young Married Women in Rural India. Maternal and child health journal, 20(6), 1203-1210. doi: 10.1007/s10995-016-1921-4

Seid, Gonzalo. (2015). La familia como ficción realizada, cuerpo integrado y campo de lucha en Pierre Bourdieu. Unidad Sociológica, 2(5), 75-83. Recuperado de http://unidadsociologica.com.ar/UnidadSociologica58.pdf

Singh, Supriya y Bhandari, Mala. (2012). Money Management and Control in the Indian Joint Family across Generations. The Sociological Review, 60(1), 46-67. doi: https://doi.org/10.1111/j.1467-954X.2011.02047.x

Stamp, Peggy. (1985). Research Note: Balance of Financial Power in Marriage: An Exploratory Study of Breadwinning Wives. The Sociological Review, 33(3), 546-557. doi: https://doi.org/10.1111/j.1467-954X.1985.tb02439.x

Vogler, Carolyn, y Pahl, Jan. (1994). Money, Power and Inequality within Marriage. The Sociological Review, 42(2), 263-288. doi: https://doi.org/10.1111/j.1467954X.1994.tb00090.x

Wainerman, Catalina. (2003). Familia, trabajo y género. Un mundo de nuevas relaciones. Buenos Aires: Fondo de Cultura Económica, Unicef.

Wilkis, Ariel y Partenio, Florencia. (2010). Dinero y obligaciones generizadas: las mujeres de sectores populares frente a las circulaciones monetarias de redes políticas y 
familiares. Revista de estudios de género, La Ventana, 4(32), 177-213. doi: https://doi.org/10.32870/lv.v4i32.857

Woolley, Frances. (2003). Control over Money in Marriage. En Shoshana A. Grossbard (Ed.), Marriage and the Economy Theory and Evidence from Advanced Industrial Societies (pp.105-128). Ottawa: Carleton University.

Zazueta Luzanilla, Edgar y Sandoval Godoy, Sergio. (2013). Concepciones de género y conflictos de pareja: Un estudio con parejas pobres heterosexuales en dos zonas urbanas de Sonora. Culturales, 1(2), 91-118.

\section{GONZALO SEID}

Es doctor en Ciencias Sociales y licenciado en Sociología por la Universidad de Buenos Aires (UBA). Becario posdoctoral del Consejo Nacional de Investigaciones Científicas y Técnicas de Argentina. Investigador a cargo del proyecto PRII de la Facultad de Ciencias Sociales (UBA) "Trayectorias de sectores medios: indicadores concurrentes y divergentes". Integrante del proyecto UBACYT "La interseccionalidad entre la etnia y el género desde la perspectiva de las clases sociales” dirigido por Gabriela Gómez Rojas.

\section{GABRiela Gómez ROJAS}

Es doctora en Ciencias Sociales (UBA), magíster en Metodología de la Investigación Científica (Universidad Nacional de Entre Ríos) y licenciada en Sociología (UBA). Dirige proyectos de investigación en temáticas de clases sociales y género en el Instituto Gino Germani de la UBA y en la Facultad de Humanidades de la Universidad Nacional de Mar del Plata (UNMdP). Se desempeña como profesora de Metodología de la Investigación en las carreras de Sociología de la UBA y de la UNMdP, y como profesora de posgrado en universidades de Argentina y otros países. 